Short Communication

\title{
Development Zinc Oxide-Cotton Fibers as Anode Materials for Lithium-Ion Batteries
}

\author{
Hongqiang Wan ${ }^{*}$, Peiying Han, Shuai Ge, Fancong Li, Simiao Zhang and Huan Li \\ Mechanical and Electrical Engineering Institute, Xi'an Technological University, Shaanxi, Xi'an, \\ 710600, China \\ *E-mail: hqwmql@ sina.cn
}

doi: $10.20964 / 2018.05 .25$

Received: 2 January 2018 / Accepted: 24 February 2018 / Published: 10 April 2018

The deposition of synthesized zinc oxide nanoparticles on the surface of cotton fiber under ultrasonic irradiation was reported in this study. The presence of the hexagonal phase of the crystalline metal oxide was confirmed by the XRD results. We also studied the electrochemical features of $\mathrm{ZnO}$ employed as an anode material for lithium-ion batteries. $\mathrm{ZnO}$ showed favorable lithium storage properties.

Keywords: Energy storage; Electrochemical performance; Cotton; Li-ion battery; Zinc oxide

\section{FULL TEXT}

(C) 2018 The Authors. Published by ESG (www.electrochemsci.org). This article is an open access article distributed under the terms and conditions of the Creative Commons Attribution license (http://creativecommons.org/licenses/by/4.0/). 